\title{
Discovery of the Crystal Phase Transition on Lead- free Cesium Manganese Bromine Perovskite Nanocrystal by Solvent Concentration
}

\section{Tae Wook Kang}

Korea Institute of Ceramic Engineering and Technology

\section{Eun Jin Choi}

Korea Institute of Ceramic Engineering and Technology

\section{Young Ji Park}

Korea Institute of Ceramic Engineering and Technology

Jonghee Hwang

Korea Institute of Ceramic Engineering and Technology

\section{Byungseo Bae}

Yeongwol Industrial Promotion Agency

\section{Sun Woog Kim ( $\nabla$ skim80@kicet.re.kr)}

Korea Institute of Ceramic Engineering and Technology

\section{Research Article}

Keywords: CsMnBr3 perovskite nanocrystals, Metal halide Cs3MnBr5 nanocrystal, Phase-tunable synthesis

Posted Date: August 13th, 2021

DOI: https://doi.org/10.21203/rs.3.rs-805887/v1

License: (c) (i) This work is licensed under a Creative Commons Attribution 4.0 International License. Read Full License 


\section{Abstract}

We have been demonstrated the crystal phase transition for lead-free cesium manganese bromine perovskite nanocrystal synthesized by the modified hot-injection method due to change the concentration of solvent (trioctylphosphine; TOP). The compositions to be synthesized were determined by the amount of TOP solvent, and the structure phase of nanocrystal was changed from hexagonal $\mathrm{CsMnBr}_{3}$ to tetragonal $\mathrm{Cs}_{3} \mathrm{MnBr}_{5}$ as the amount of TOP solvent increased. The emission peaks of $\mathrm{CsMnBr}_{3}$ and $\mathrm{Cs}_{3} \mathrm{MnBr}_{5}$ nanocrystals were observed at $650 \mathrm{~nm}$ (red) and $520 \mathrm{~nm}$ (green), respectively. After a durability test at $85^{\circ} \mathrm{C}$ and $85 \%$ humidity for $24 \mathrm{~h}$, the lead-free perovskite $\mathrm{CsMnBr}_{3}$ nanocrystal powder maintained its initial emission intensity, and the metal halide $\mathrm{Cs}_{3} \mathrm{MnBr}_{5}$ nanocrystal powder exhibited an increase in red emission due to the post-synthesis of $\mathrm{CsMnBr}_{3}$ nanocrystals.

\section{Introduction}

Lead halide perovskites, which have the general formula $\mathrm{APbX}_{3}$ (where $\mathrm{A}=\mathrm{CH}_{3} \mathrm{NH}_{3}{ }^{+}(\mathrm{MA}), \mathrm{HC}\left(\mathrm{NH}_{2}\right)_{2}{ }^{+}$ $(\mathrm{FA})$, or $\mathrm{Cs}^{+} ; \mathrm{X}=\mathrm{Cl}, \mathrm{Br}$ or I), has been studied since the middle of the 20th century [1-5]. Among these perovskites, inorganic cesium lead halide perovskite $\left(\mathrm{Cs}_{n} \mathrm{PbX}_{2+n}, \mathrm{X}=\mathrm{Cl}, \mathrm{Br}\right.$, l, or a mixture thereof) nanocrystals have attracted significant attention as an optical material for display and lamp applications (e.g. color converter material), as an alternative to quantum dot materials. Within the past decade, there have been rapid advances in the synthesis of cesium lead halide perovskite nanocrystals for use in solar cells, light-emitting diodes (LEDs), lasers, and photodetectors because of the excellent optoelectronic performance of these perovskite nanocrystals [6-13]. They have interesting optical, excitonic, and charge-transport properties, including an outstanding photoluminescence quantum yield (PLQY) and tunable optical bandgap.

Despite these advantages, however, the presence of $\mathrm{Pb}$, a toxic element, in perovskite nanocrystals raises critical concerns with regard to commercialization. This is because the heavy metal $\mathrm{Pb}$ can affect human health and the environment $[14,15]$. The US EPA has set the maximum allowable content of $\mathrm{Pb}$ in air and water as $0.15 \mu \mathrm{g} / \mathrm{L}$ and $15 \mu \mathrm{g} / \mathrm{L}$, respectively. The European Union regulates the use of heavy and toxic materials (including $\mathrm{Pb}$ ) in electronic devices, and the use of lead-based technology is expected to decline in the future $[16,17]$ Therefore, the development of a lead-free cesium halide perovskite that retains the outstanding properties of cesium lead halide nanocrystals is important, and several studies have been conducted recently in this regard.

Metallic elements that have an electronic structure similar to that of $\mathrm{Pb}$ and can thus form stable perovskite structures-such as $\mathrm{Sn}, \mathrm{Sb}, \mathrm{Bi}, \mathrm{Eu}$, and $\mathrm{Yb}$-have been considered as alternatives for $\mathrm{Pb}$. Various lead-free halide perovskite nanocrystals, including those containing the aforementioned metal elements, have recently been developed and have achieved optoelectronic performance comparable to that of $\mathrm{Pb}$-based counterparts [17-19]. These encouraging results obtained via exploration of lead-free 
perovskite nanocrystals indicate a major imminent breakthrough in the fabrication of new optoelectronic devices.

In this study, to obtain lead-free inorganic halide perovskite nanocrystals, we focused on replacing $\mathrm{Pb}$ with the transition metal $\mathrm{Mn}$. Mn has an ionic radius ( $0.083 \mathrm{~nm}$ for 6 coordination) similar to that of $\mathrm{Pb}$ $(0.119 \mathrm{~nm}$ for 6 coordination), as well as a low toxicity, and has therefore attracted attention as a substitute for the $B$ site in halide perovskites. Cesium manganese bromide perovskite nanocrystals, such as the red-emitting $\mathrm{CsMnBr}_{3}$ and green-emitting $\mathrm{Cs}_{3} \mathrm{MnBr}_{5}$, have been reported to exhibit excellent optical properties [20-23]. In this paper, we synthesized red-emitting $\mathrm{CsMnBr}_{3}$ and $\mathrm{Cs}_{3} \mathrm{MnBr}_{5}$ perovskite nanocrystals using the modified hot-injection method and investigated the optical properties of these perovskite nanocrystals. Furthermore, we investigated the phase-tunable synthesis from $\mathrm{Cs}_{3} \mathrm{MnBr}_{5}$ to $\mathrm{CsMnBr} 3$ with controlling the amount of solvent.

\section{Results And Discussion}

Figure 1 shows the XRD patterns of the cesium manganese bromide perovskite nanocrystals with the amount of TOP solvent as well as the standard XRD patterns of the $\mathrm{CsMnBr}_{3}$ and $\mathrm{Cs}_{3} \mathrm{MnBr}_{5}$ from JCPDS card No. 26-0387 and No. 27-0117, respectively. The crystal structures of $\mathrm{CsMnBr}_{3}$ and $\mathrm{Cs}_{3} \mathrm{MnBr}_{5}$ are shown in Fig. 2. The crystal structure of $\mathrm{CsMnBr}_{3}$ consists of linear chains of distorted face-sharing $\left[\mathrm{MnBr}_{6}\right]$ octahedron with a $\mathrm{D}_{3 \mathrm{~d}}$ symmetry parallel to the c-axis, that are bridged by $\mathrm{Cs}$ ions. Interestingly, the $\mathrm{Mn}-\mathrm{Mn}$ distance is very short ( $0.32982 \mathrm{~nm})$ along the c-axis, leading to strongly coupled optical transitions. The XRD pattern of the sample prepared with $10 \mathrm{~mL}$ TOP solvent was indexed to the standard hexagonal $\mathrm{CsMnBr}_{3}$ structure (JCPDS No. 26-0387); this sample contains the $\mathrm{P}_{3} / \mathrm{mmc}$ (\#194) space group and has lattice parameters $a=b=0.785878 \mathrm{~nm}$ and $c=0.659641 \mathrm{~nm}$. In the crystal structure of $\mathrm{Cs}_{3} \mathrm{MnBr}_{5}$, the $\mathrm{Mn}^{2+}$ ions are coordinated by four $\mathrm{Br}$ ions to form a $\left[\mathrm{MnBr}_{4}\right]$ regular tetrahedron geometry with $\mathrm{D}_{2 \mathrm{~d}}$ symmetry. The $\mathrm{Mn}^{2+}$ site layers are separated by $\mathrm{Cs}^{+}$site layers in the direction of the c-axis, and the adjacent $\left[\mathrm{MnBr}_{4}\right]$ tetrahedrons maintain a distance of $0.780593(6) \mathrm{nm}$. The XRD pattern of the sample prepared with $20 \mathrm{~mL}$ TOP solvent corresponds to a single-phase tetragonal $\mathrm{Cs}_{3} \mathrm{MnBr}_{5}$ structure (JCPDS No. 27-0117); this sample has the $14 / \mathrm{mcm}$ (\#140) space group and lattice constants $\mathrm{a}=\mathrm{b}=$ $0.992839 \mathrm{~nm}$ and $\mathrm{c}=1.561187 \mathrm{~nm}$. The nanocrystal samples prepared with 12.5 and $17.5 \mathrm{~mL}$ TOP solvent exhibit a mixed phase with hexagonal $\mathrm{CsMnBr}_{3}$ and tetragonal $\mathrm{Cs}_{3} \mathrm{MnBr}_{5}$ phases, and the phase transition of nanocrystal phase from $\mathrm{CsMnBr}_{3}$ to $\mathrm{Cs}_{3} \mathrm{MnBr}_{5}$ was observed as the amount of TOP solvent increased.

The morphology of the synthesized nanocrystals with the amount of TOP solvent was analyzed using high-resolution TEM, as shown in Fig. 3. The TEM images of lead-free perovskite $\mathrm{CsMnBr}_{3}$ nanocrystals present a dispersed hexagonal morphology with an average size of $\sim 20 \mathrm{~nm}$. The interplanar spacing relative to the (021) crystalline planes of the $\mathrm{CsMnBr}_{3}$ nanocrystals is about $0.3 \mathrm{~nm}$. In contrast, the TEM image of $\mathrm{Cs}_{3} \mathrm{MnBr}_{5}$ nanocrystals shows a dispersed tetragonal morphology with an average size of $\sim 30$ 
$\mathrm{nm}$. The interplanar spacing relative to the (213) crystalline planes of the $\mathrm{Cs}_{3} \mathrm{MnBr}_{5}$ nanocrystals is about $0.33 \mathrm{~nm}$. The nanocrystals prepared with 12.5 and $17.5 \mathrm{~mL}$ TOP solvent coexist with the $\mathrm{CsMnBr}_{3}$ and $\mathrm{Cs}_{3} \mathrm{MnBr}_{5}$ nanocrystals; the compositional change between the $\mathrm{CsMnBr}$ and $\mathrm{Cs}_{3} \mathrm{MnBr}_{5}$ nanocrystals is determined by the amount of TOP solvent.

Figure 4 presents the PL spectra of the obtained nanocrystals with the amount of TOP solvent. The inset images show the emission of the nanocrystals under irradiation with a $365 \mathrm{~nm}$ UV lamp; their color changes from red to green as the amount of TOP solvent increases from 10 to $20 \mathrm{~mL}$. The emission spectrum of the lead-free perovskite $\mathrm{CsMnBr}_{3}$ nanocrystals exhibits a broad red emission peak centered at $650 \mathrm{~nm}$ with a full-width-at-half-maximum (FWHM) of $95 \mathrm{~nm}$. The red PL emission which assigned ${ }^{4} \mathrm{~T}_{1} \rightarrow{ }^{6} \mathrm{~A}_{1}$ transition in $\left[\mathrm{MnBr}_{6}\right]^{4-}$ octahedrons of the $\mathrm{CsMnBr}_{3}$ nanocrystals is considered to be due to the relaxation from the lowest excited state to the ground state of $\mathrm{Mn}^{2+}$ ions. This is consistent with reports of red emission from $\mathrm{Mn}^{2+}$ in the $\mathrm{MnBr}_{6}$ octahedron [24, 25]. On the other hand, the emission spectrum of the $\mathrm{Cs}_{3} \mathrm{MnBr}_{5}$ nanocrystals shows green emission at $520 \mathrm{~nm}$ with an FWHM of $50 \mathrm{~nm}$. The strong green emission is ascribed to the metal-centered $d-d$ transition of the $\mathrm{Mn}^{2+}$ ion in the $d^{5}$ configuration with a $\left[\mathrm{MnBr}_{4}\right]$ tetrahedral coordination geometry [26]. Interestingly, the $\mathrm{PL}$ spectra of the Cs-Mn-Br nanocrystals can be controlled by simply changing the amount of TOP solvent, as depicted in Fig. 4. With an increase of the amount of TOP solvent, the relative emission of red $\left(\mathrm{CsMnBr}_{3}\right)$ and green $\left(\mathrm{Cs}_{3} \mathrm{MnBr}_{5}\right)$ shifts toward green emission, implying that our study can achieve tunable the color between green and red by simply controlling the amount of TOP solvent.

To evaluate the thermal and chemical stability of the $\mathrm{CsMnBr}_{3}$ and $\mathrm{Cs}_{3} \mathrm{MnBr}_{5}$ nanocrystals, a durability test was performed under high-temperature and high-humidity conditions of $85^{\circ} \mathrm{C}$ and $85 \%$, respectively, for $24 \mathrm{~h}$. The PL behaviors of the $\mathrm{CsMnBr}_{3}$ and $\mathrm{Cs}_{3} \mathrm{MnBr}_{5}$ nanocrystals after the durability test are shown in Fig. 5 (a). The lead-free perovskite $\mathrm{CsMnBr}_{3}$ nanocrystal powder exhibits extremely high durability and maintains its initial PL intensity. In comparison, the PL intensity of the metal halide $\mathrm{Cs}_{3} \mathrm{MnBr}_{5}$ nanocrystal powder does not decrease but rather increases in the red emission $\left(\mathrm{CsMnBr}_{3}\right)$ region. It is considered that the materials that remained unreacted during the preparation of the nanocrystals reacted to form more $\mathrm{CsMnBr}_{3}$ nanocrystals due to the high temperature during the durability test. Both nanocrystals exhibited no change in the PL peak wavelength and FWHM values after the durability test. The structures of $\mathrm{CsMnBr}_{3}$ and $\mathrm{Cs}_{3} \mathrm{MnBr}_{5}$ are considered to have remained intact even after the durability test because no difference was observed between the XRD patterns before and after the test. The XRD patterns of the $\mathrm{CsMnBr}_{3}$ and $\mathrm{Cs}_{3} \mathrm{MnBr}_{5}$ nanocrystals before and after the durability test are presented in Fig. 5 (b). Both samples exhibited identical XRD patterns before and after the test, indicating that the CsMnBr 3 and $\mathrm{Cs}_{3} \mathrm{MnBr}_{5}$ structures were not degraded during the durability test.

\section{Conclusions}


We discovered the crystal phase transition of lead-free cesium manganese bromine perovskite nanocrystal from hexagonal $\mathrm{CsMnBr}_{3}$ to tetragonal $\mathrm{Cs}_{3} \mathrm{MnBr}_{5}$ due to change the concentration of TOP solvent for the first time. The $\mathrm{CsMnBr}_{3}$ nanocrystals had a hexagonal structure and exhibited a dispersed hexagonal morphology with an average size of $\sim 20 \mathrm{~nm}$ and an interplanar spacing of $0.3 \mathrm{~nm}$. The $\mathrm{Cs}_{3} \mathrm{MnBr}_{5}$ nanocrystals had a tetragonal structure and exhibiting a dispersed tetragonal morphology with an average size of $\sim 30 \mathrm{~nm}$ and an interplanar spacing of $0.33 \mathrm{~nm}$. The compositional change between the $\mathrm{CsMnBr}_{3}$ and $\mathrm{Cs}_{3} \mathrm{MnBr}_{5}$ nanocrystals was determined by the amount of TOP solvent, the nanocrystal phase is changed from $\mathrm{CsMnBr}_{3}$ to $\mathrm{Cs}_{3} \mathrm{MnBr}_{5}$ as the amount of TOP increases. The emission peaks of the $\mathrm{CsMnBr}_{3}$ and $\mathrm{Cs}_{3} \mathrm{MnBr}_{5}$ nanocrystals were observed to be at $650 \mathrm{~nm}(\mathrm{FWHM}=95 \mathrm{~nm})$ and $520 \mathrm{~nm}$ $(F W H M=50 \mathrm{~nm})$, respectively. With an increase in the amount of TOP solvent, the relative emission of red $\left(\mathrm{CsMnBr}_{3}\right)$ and green $\left(\mathrm{Cs}_{3} \mathrm{MnBr}_{5}\right)$ shifted toward green emission. To examine the stability of the lead-free cesium manganese bromine perovskite nanocrystals, durability tests were performed. The $\mathrm{CsMnBr}_{3}$ and $\mathrm{Cs}_{3} \mathrm{MnBr}_{5}$ nanocrystal powders fabricated from the nanocrystal solutions were subjected to hightemperature and high-humidity testing at $85^{\circ} \mathrm{C}$ and $85 \%$ humidity for $24 \mathrm{~h}$. After the durability test, no change was observed in the PL intensity of the lead-free perovskite $\mathrm{CsMnBr}_{3}$ nanocrystal however, an increase in red emission was observed for the metal halide $\mathrm{Cs}_{3} \mathrm{MnBr}_{5}$ nanocrystal. Our study demonstrates that phase-tunable synthesis between lead-free perovskite $\mathrm{CsMnBr}_{3}$ and metal halide $\mathrm{Cs}_{3} \mathrm{MnBr}_{5}$ nanocrystals can be easily achieved by controlling the amount of TOP solvent; it's material represents a potential next-generation luminescence material for mini LED devices and applications in optoelectronic devices.

\section{Method}

Materials Cesium carbonate $\left(\mathrm{Cs}_{2} \mathrm{CO}_{3}\right.$, purity; $\left.99.995 \%\right)$, manganese(II) bromide $\left(\mathrm{MnBr}_{2}\right.$, purity; $\left.98 \%\right), 1$ octadecene (ODE, technical grade; 90\%), trioctylphosphine (TOP, technical grade; 90\%), oleic acid (OA, technical grade; $90 \%$ ), and oleylamine (OLA, technical grade; $90 \%$ ) were purchased from Aldrich.

Synthesis of $\mathrm{CsMnBr}_{3}$ and $\mathrm{Cs}_{3} \mathrm{MnBr}_{5}$ nanocrystal Cs-oleate was prepared by mixing $0.13 \mathrm{~g} \mathrm{Cs}_{2} \mathrm{CO}_{3}, 0.55$ $\mathrm{mL} O A, 0.4 \mathrm{~mL} O L A$, and $12 \mathrm{~mL} O D E$ in a $30 \mathrm{~mL}$ glass vial for $1 \mathrm{~h}$ at $170^{\circ} \mathrm{C}$ for dissolution. The solution containing $\mathrm{MnBr}_{2}$ was prepared by mixing $0.5369 \mathrm{~g} \mathrm{MnBr}_{2}$ and $5-20 \mathrm{~mL}$ TOP in a $30 \mathrm{~mL}$ glass vial at $170^{\circ} \mathrm{C}$ for $1 \mathrm{~h}$; then, Cs-oleate was quickly injected into the solution containing $\mathrm{MnBr}_{2}$. The $\mathrm{CsMnBr}_{3}$ or $\mathrm{Cs}_{3} \mathrm{MnBr}_{5}$ nanocrystal solutions reacted at $170^{\circ} \mathrm{C}$ for $1 \mathrm{~min}$ and were cooled in an ice-water bath to suppress the crystal growth of the nanocrystals. The obtained $\mathrm{CsMnBr}_{3} / \mathrm{Cs}_{3} \mathrm{MnBr}_{5}$ nanocrystal solution was separated via centrifugation at $4000 \mathrm{rpm}$ for $5 \mathrm{~min}$.

Characterizations The crystal structure of the $\mathrm{CsMnBr}_{3}$ and $\mathrm{Cs}_{3} \mathrm{MnBr}_{5}$ nanocrystal was identified using Xray powder diffraction (XRD; Rigaku SmartLab) analysis, and the microstructure and morphology of the nanocrystals was characterized using transmission electron microscopy (TEM; JEOL). The photoluminescence $(\mathrm{PL})$ spectrum was recorded at room temperature using a fluorescence 
spectrophotometer (PSI, DARSA PRO-3400), and the emission spectrum was obtained at an excitation wavelength of $365 \mathrm{~nm}$. The lead-free cesium manganese bromine perovskite nanocrystal powder was prepared using the nanocrystal solution; a durability test was performed at $85^{\circ} \mathrm{C}$ and $85 \%$ humidity for 24 h.

\section{Declarations}

\section{Acknowledgement}

This research was financially supported by the Ministry of Trade, Industry and Energy (MOTIE) and Korea Institute for Advancement of Technology (KIAT) through the International Cooperative R\&D program (P0006844_Development of color conversion nanocrystal luminescence materials for next generation display).

\section{Author Contributions}

T. W. Kang, J. Hwang, B. S. Bae and S. W. Kim, contributed to the design experiments, interpreted the data and prepared the paper. E. J. Choi and Y. J. Park contributed to the experiments. All authors discussed the results and reviewed the manuscript.

\section{Additional Information}

The authors declare no competing financial interest.

\section{References}

1. MØLLER, C. K. Crystal structure and photoconductivity of caesium plumbohalides. Nature 182, 1436 (1958).

2. Poglitsch, A. \& Weber, D. Dynamic disorder in methylammonium- trihalogenoplumbates (II) observed by millimeter-wave spectroscopy. J. Chem. Phy. 87, 6373-6378 (1987).

3. Weber, D. $\mathrm{CH}_{3} \mathrm{NH}_{3} \mathrm{PbX}$, ein $\mathrm{Pb}(\mathrm{II})$-System mit kubischer Perowskitstruktur/ $\mathrm{CH}_{3} \mathrm{NH}_{3} \mathrm{PbX}$, a $\mathrm{Pb}(\mathrm{II})$ System with Cubic Perovskite Structure. Naturforsch. B 33, 1443-1445 (1978).

4. Onoda-Yamamuro, N., Matsuo, T. \& Suga, H. Dielectric study of $\mathrm{CH}_{3} \mathrm{NH}_{3} \mathrm{PbX}_{3}(\mathrm{X}=\mathrm{Cl}, \mathrm{Br}$, I). J. Phys. Chem. Solids 53, 935-939 (1992).

5. Papavassiliou, G. C. \& Koutselas, I. B. Structural, optical and related properties of some natural threeand lower-dimensional semiconductor systems. Synth. Met. 71, 1713-1714 (1995).

6. Song, J., Li, J., Li, X., Xu, L., Dong, Y. \& Zeng, H. Quantum Dot Light-Emitting Diodes Based on Inorganic Perovskite Cesium Lead Halides (CsPbX 3 ). Adv. Mater. 27, $7162-7167$ (2015).

7. Pan, J., et al. Highly Efficient Perovskite-Quantum-Dot Light-Emitting Diodes by Surface Engineering. Adv. Mater. 28, 8718-8725 (2016). 
8. Zhang, X., et al. Enhancing the Brightness of Cesium Lead Halide Perovskite Nanocrystal Based Green Light-Emitting Devices through the Interface Engineering with Perfluorinated Ionomer. Nano Lett. 16, 1415-1420 (2016).

9. Wang, Y., Li, X., Song, J., Xiao, L., Zeng, H. \&Sun, H. All-Inorganic Colloidal Perovskite Quantum Dots: A New Class of Lasing Materials with Favorable Characteristics. Adv. Mater. 27, 7101-7108 (2016).

10. Li, X., et al. Healing All-Inorganic Perovskite Films via Recyclable Dissolution- Recyrstallization for Compact and Smooth Carrier Channels of Optoelectronic Devices with High Stability. Adv. Funct. Mater. 26, 5903-5912 (2016).

11. Ramasamy, P., Lim, D. H., Kim, B., Lee, S. H., Lee, M. S. \& Lee, J. S. All-inorganic cesium lead halide perovskite nanocrystals for photodetector applications. Chem. Commun. 52, 2067-2070 (2016).

12. Protesescu, L., et al. Nanocrystals of Cesium Lead Halide Perovskites ( $\mathrm{CsPbX}_{3}, \mathrm{X}=\mathrm{Cl}, \mathrm{Br}$, and I): Novel Optoelectronic Materials Showing Bright Emission with Wide Color Gamut. Nano Lett. 15, 3692-3696 (2015).

13. Kulkarni, S. A., Mhaisalkar, S. G., Mathews, N. \& Boix, P. P. Perovskite nanoparticles: synthesis, properties, and novel applications in photovoltaics and LEDs. Small Methods 3, 1800231 (2019).

14. Kamat, P. V., Bisquert, J. \& Buriak, J. Lead-free perovskite solar cells. ACS Energy Letters 2, 904-905 (2017).

15. McDonald, C., et al. Nanostructured perovskite solar cells. Nanomaterials 9, 1481 (2019).

16. Takenaka, T. \& Nagata, H. Current status and prospects of lead-free piezoelectric ceramics. J. Eur. Ceram. Soc. 25, 2693-2700 (2005).

17. Shi, Z., et al. Lead-free organic-inorganic hybrid perovskites for photovoltaic applications: recent advances and perspectives. Adv. Mater. 29, 1605005 (2017).

18. Hao, F., Stoumpos, C. C., Cao, D. H., Chang, R. P. H. \& Kanatzidis, M. G. Lead-free solid-state organicinorganic halide perovskite solar cells. Nat. Photonics 8, 489-494 (2014).

19. Ju, M. G., Dai, J., Ma, L. \& Zeng, X. C. Lead-Free Mixed Tin and Germanium Perovskites for Photovoltaic Application. J. Am. Chem. Soc. 139, 8038-8043 (2017).

20. Almutlaq, J., et al. CsMnBr 3 : Lead-Free Nanocrystals with High Photoluminescence Quantum Yield and Picosecond Radiative Lifetime. ACS Materials Lett. 3, 290-297 (2021).

21. Su, B., Molokeev, M. S. \& Xia, Z. $\mathrm{Mn}^{2+}{ }_{-}$Based narrow-band green-emitting $\mathrm{Cs}_{3} \mathrm{MnBr}_{5}$ phosphor and the performance optimization by $\mathrm{Zn}^{2+}$ alloying. J. Mater. Chem. C 7, 11220-11226 (2019).

22. Shao, L., et al. Broadband Ultraviolet Photodetectors Based on Cerium Doped Lead-Free $\mathrm{Cs}_{3} \mathrm{MnBr}_{5}$ Metal Halide Nanocrystals. ACS Sustainable Chem. Eng. 9, 4980-4987 (2021).

23. Kwon, S. B., et al. Organic solvent-free lyophilization assisted recrystallization synthesis of highpurity green emissive $\mathrm{Cs}_{3} \mathrm{MnX}_{5}(\mathrm{X}=\mathrm{I}, \mathrm{Br})$. J. Alloy Compd. 845, 156324 (2020).

24. Lin, J., et al. Atomically Precise Doping of Monomanganese Ion into Coreless Supertetrahedral Chalcogenide Nanocluster Inducing Unusual Red Shift in $\mathrm{Mn}^{2+}$ Emission. J. Am. Chem. Soc. 136, 4769-4779 (2014). 
25. Orive, J., et al. Enhancement of the Luminescent Properties of a New Red-Emitting Phosphor, $\mathrm{Mn}_{2}\left(\mathrm{HPO}_{3}\right) \mathrm{F}_{2}$, by Zn Substitution. Inorg. Chem. 50, 12463-12476 (2011).

26. Palumbo, D. T. \& Brown, J. J. Electronic States of $\mathrm{Mn}^{2+}$-Activated Phosphors.: I. Green-Emitting Phosphors. J. Electrochem. Soc. 117, 1184-1188 (1970).

\section{Figures}

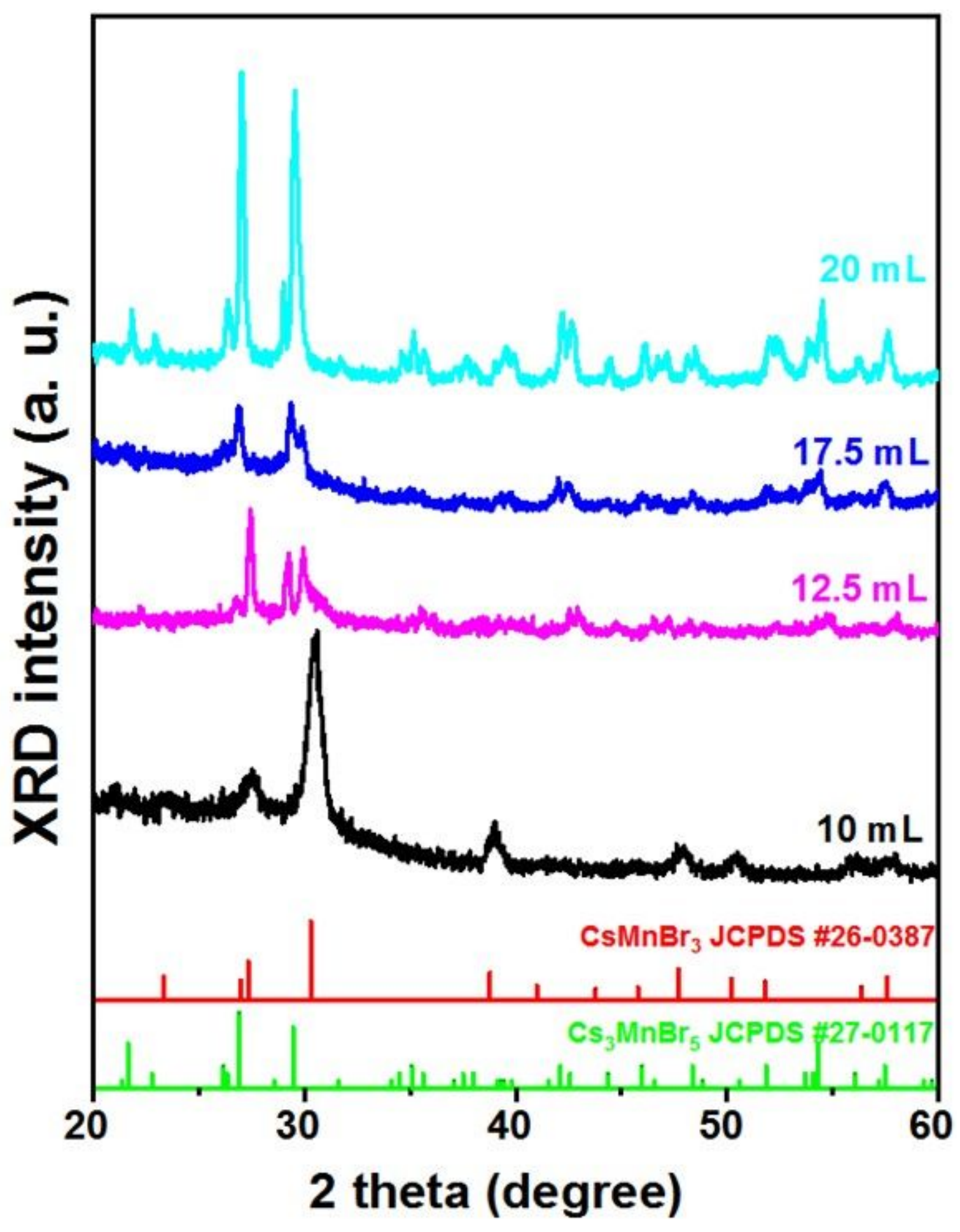

Figure 1 
XRD patterns of the lead-free cesium manganese bromine perovskite nanocrystals by modified hotinjection method with the amount of TOP solvent.

(a)

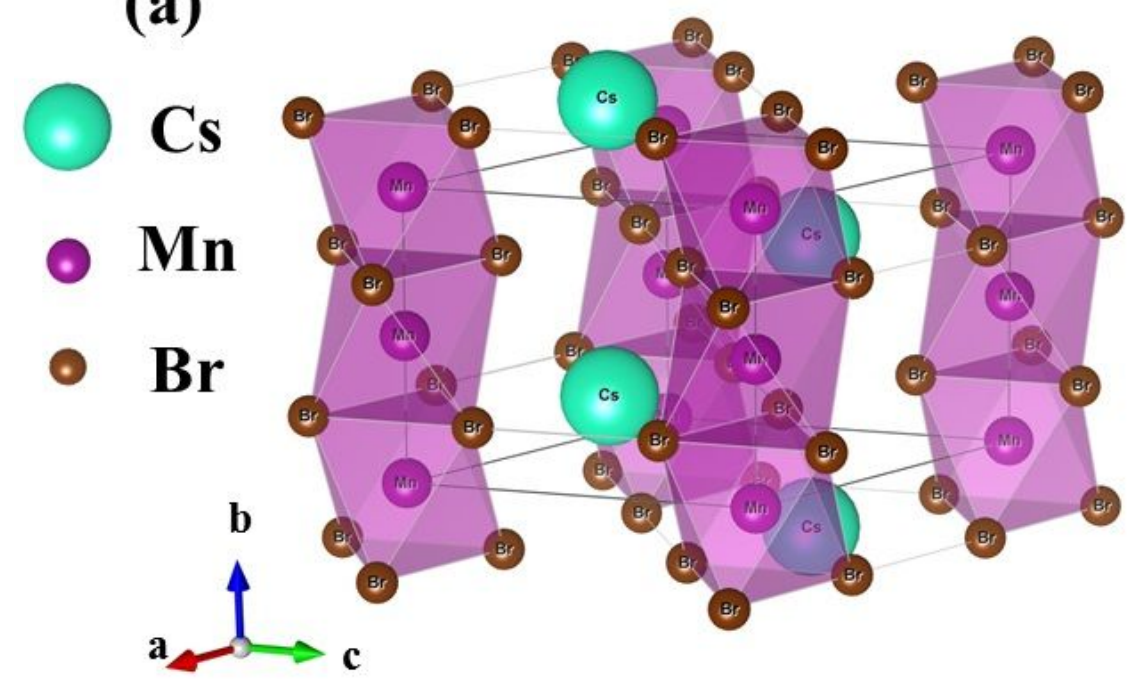

(c)

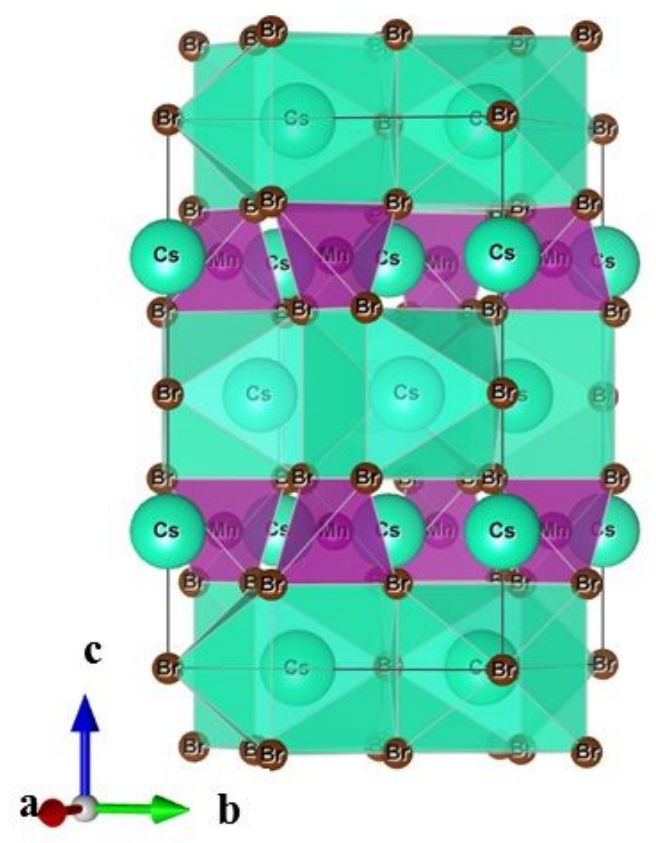

(b)

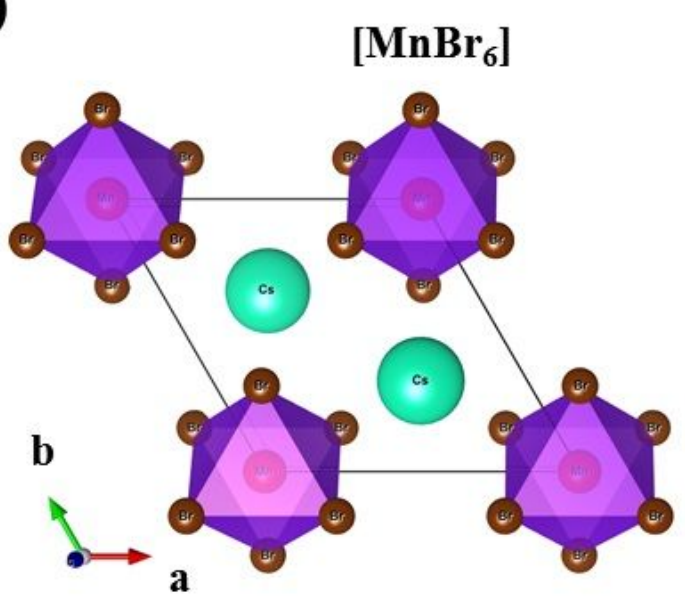

(d)

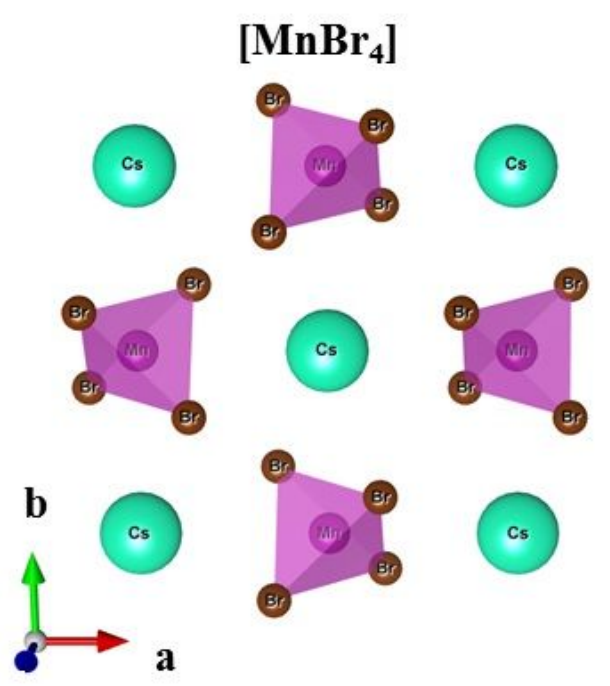

\section{Figure 2}

Schematic of (a) CsMnBr3 crystal structure with (b) the ab plane illustrating the octahedral coordination of $\mathrm{Mn} 2+$, and (c) Cs3MnBr5 crystal structure with (d) the ab plane illustrating the tetrahedral coordination of $\mathrm{Mn} 2+$. 


\section{(a) $\mathrm{CsMnBr}_{3}(10 \mathrm{~mL}$ TOP)}

(b) $\mathrm{Cs}_{3} \mathrm{MnBr}_{5}(20 \mathrm{~mL} \mathrm{TOP})$

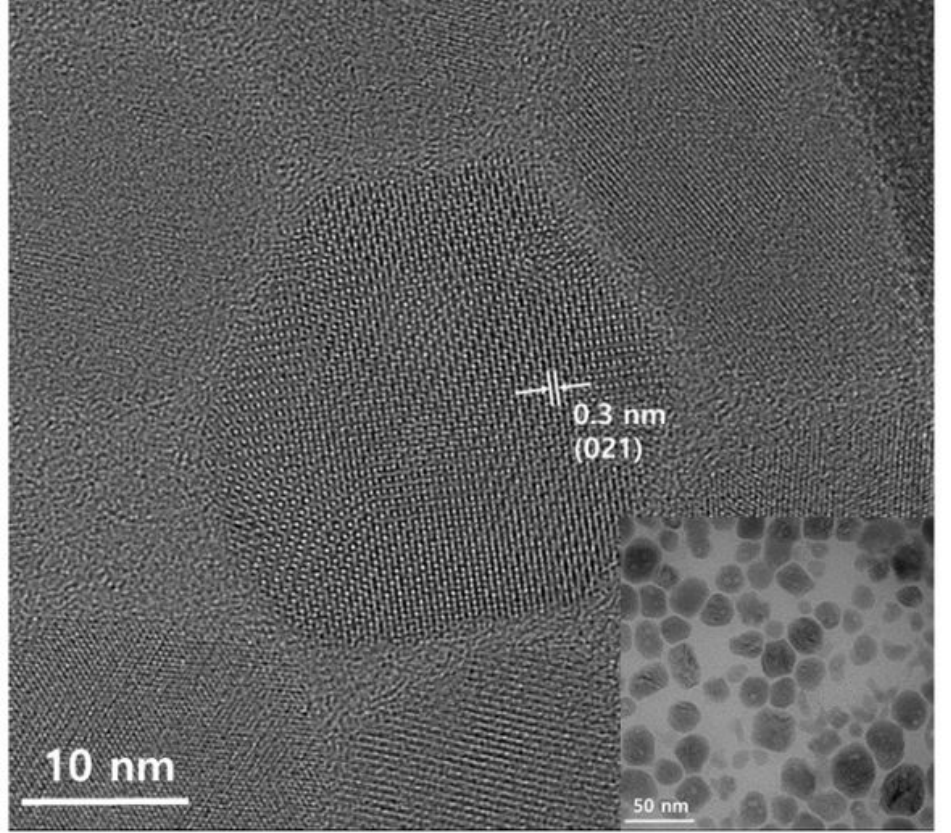

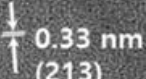

(213)

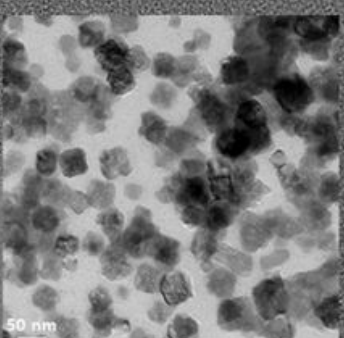

\section{Figure 3}

Low- and high-resolution TEM images of the synthesized nanocrystals prepared using different amount of TOP solvent: (a) CsMnBr3 (10 mL), (b) Cs3MnBr5 (20 mL). 


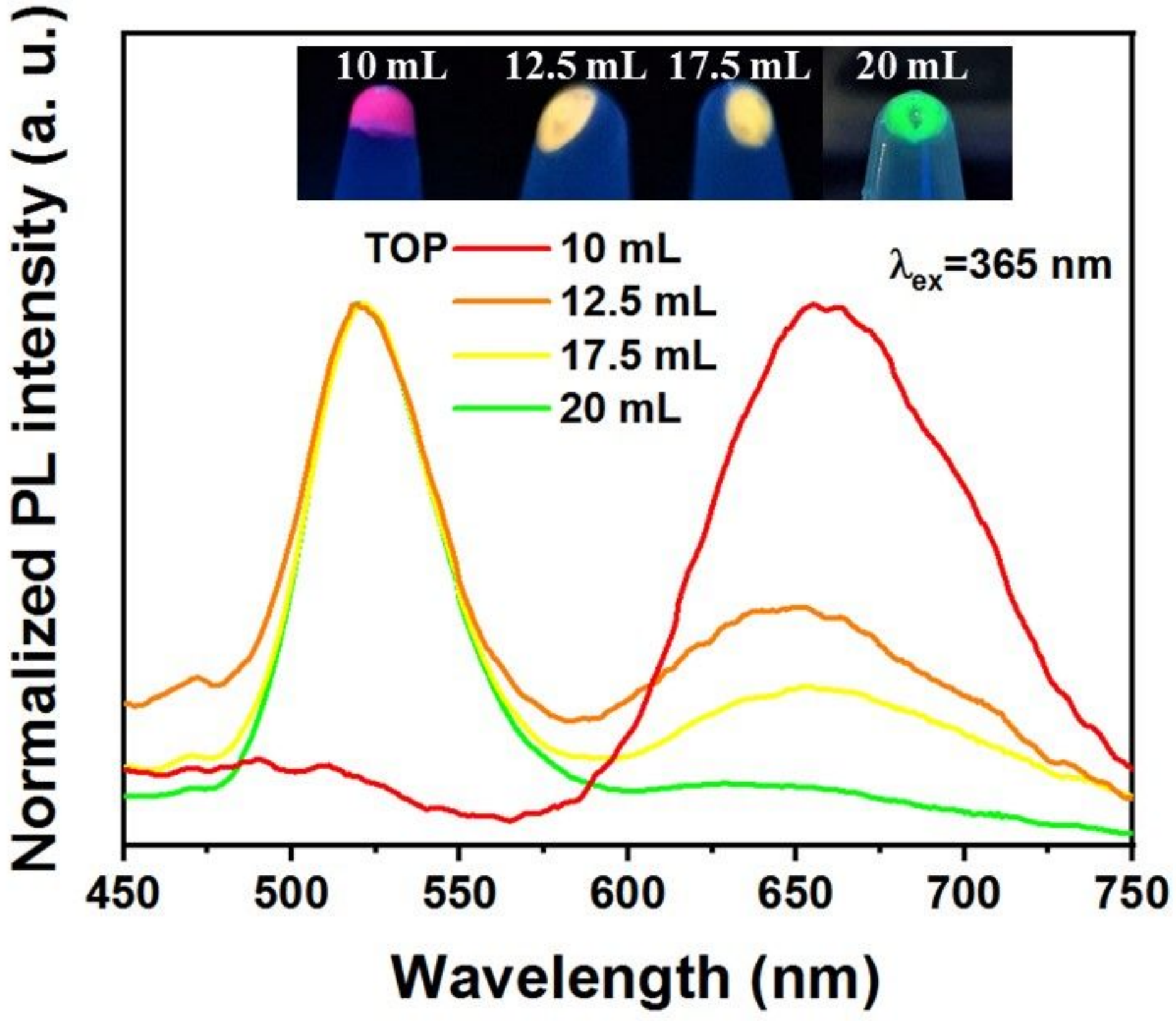

Figure 4

$\mathrm{PL}$ spectra of CsMnBr3 and Cs3MnBr5 nanocrystals with the amount of TOP solvent. 

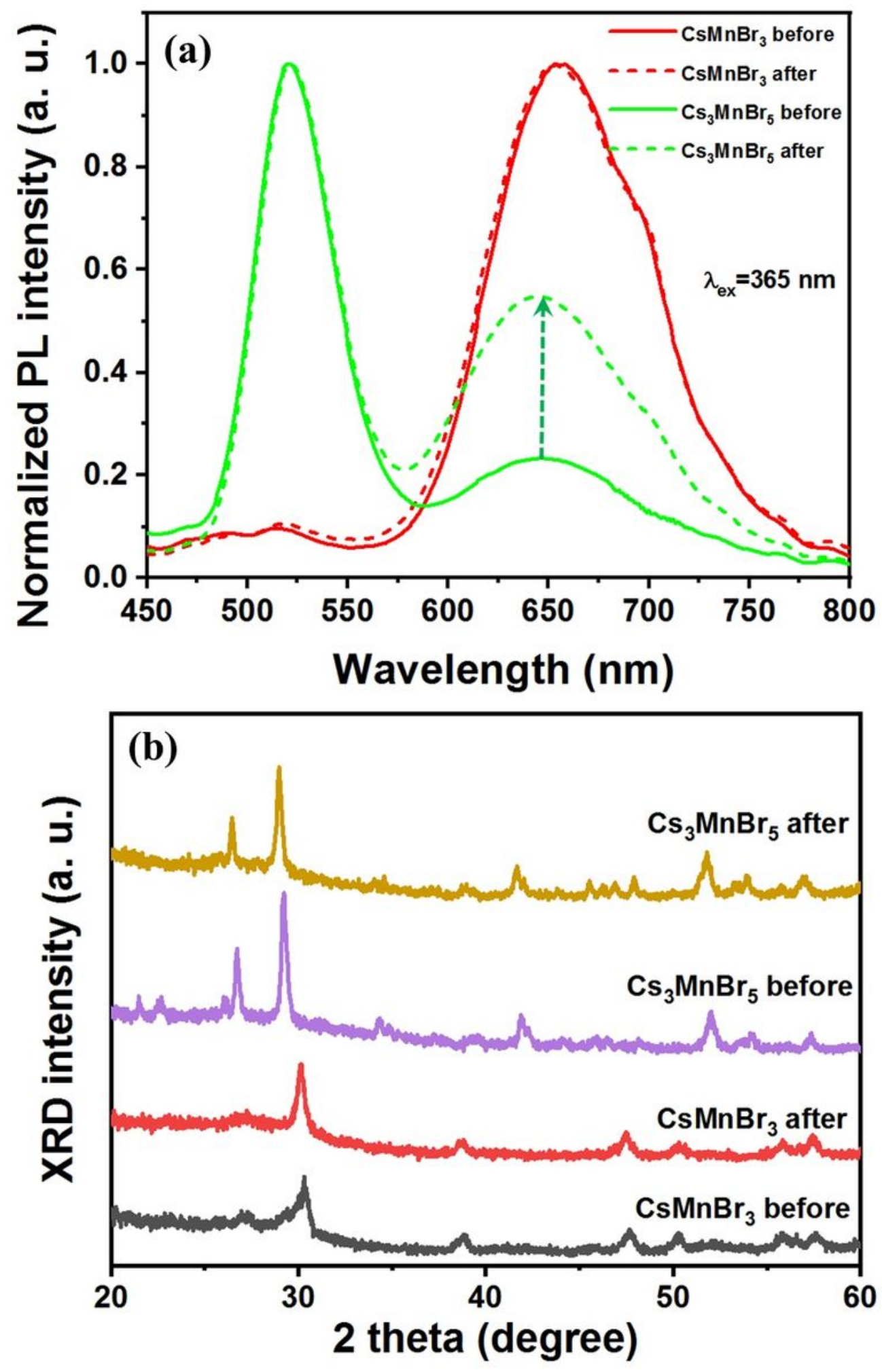

Figure 5

(a) PL spectra of the high-temperature and high-humidity testing of lead-free perovskite $\mathrm{CsMnBr} 3$ (red) and metal halide Cs3MnBr5 (green) nanocrystals at $85^{\circ} \mathrm{C}$ and $85 \%$ humidity for $24 \mathrm{~h}$, and (b) XRD patterns of the $\mathrm{CsMnBr} 3$ and $\mathrm{Cs} 3 \mathrm{MnBr} 5$ nanocrystals before and after the durability test. 